\title{
A reforma educacional paulista e a "nova" cultura docente
}

The educational reform in the state of São Paulo and the

"new" teaching culture

Gisela do Carmo Lourencetti*

Centro Universitário Moura Lacerda

Resumo O ideário neoliberal, as mudanças sociais e educacionais compõem o referencial desta pesquisa, que investigou indícios de alteração na cultura docente dos professores secundários, principalmente após a implantação da reforma educacional paulista. Considerando a formação recebida pelos docentes e comparando o papel que os professores desempenhavam no passado, parece que estamos diante de uma nova especificidade do trabalho, decorrente da ampliação desse papel. Os professores procuram conciliar, ao ensino dos conteúdos específicos, um papel afetivo, de socialização e abandonam o aspecto acadêmico como central. Observa-se também que os professores reconhecem que diminuíram o grau de exigência, após a implantação da Progressão Continuada nas escolas estaduais. Identificamos um aspecto decisivo: além da configuração da "nova" cultura docente há indícios de um grave processo de enfraquecimento da escola.

PalaVras-Chave: Reforma educacional, Trabalho docente, Professor.

Abstract The neoliberal ideology and the social and educational changes constitute the references for this study which investigated indications of change in the teaching culture of secondary school teachers, mainly after the implementation of the educational reform in the state of São Paulo. Considering the training that teachers now receive and comparing it to their role in the past, it seems that the work has acquired a new specificity, resulting from the expansion of this work. Teachers seek to conciliate a role of affection and socialization with the teaching of specific contents and abandon the academic aspect as central. It was also observed that teachers acknowledge that there is a decrease in the requirements after the implementation of the Continued Progression in state schools. A decisive aspect was identified: besides the configuration of the "new" teaching culture there are indications of a serious process of deterioration of schools.

KEYWORDS: Educational reform, Teaching work, Teacher. 
Para entender o professor e seu trabalho hoje é necessário considerar o contexto social e político em que eles estão incluídos. Voltando a um passado recente, percebemos que mudanças ocorreram, interferiram na sociedade brasileira e repercutiram na vida dos professores e das escolas. Com os diversos meios de comunicação formaram-se redes de informação cada vez mais internacionalizadas e ágeis e com isso minimizou-se o monopólio da transmissão de conhecimentos pela escola.

Os professores nesse contexto também são diferentes do clássico professor do passado. Segundo Gatti, Barreto e André (2011, p. 28), "atualmente no Brasil, os próprios professores são provenientes de camadas sociais menos favorecidas, com menor favorecimento educacional”.

O mal-estar docente analisado por Esteve (1995) e a sensação de frustração física e emocional são também características do trabalho docente. Isso se deve às condições de trabalho que impõe ao professor uma sobrecarga de trabalho. O somatório desses aspectos pode ser configurado como o processo de intensificação do trabalho docente (APPLE, 1995; HYPÓLITO, 1999; CUNHA, 1999).

Hypólito, Vieira e Pizzi (2009) defendem a necessidade de se entender o conceito de intensificação do trabalho para melhor compreendermos a docência na atualidade. Para os autores há um aumento do controle sobre o trabalho de ensinar e um declínio de sua autonomia quanto às decisões pedagógicas.

Nesse contexto, não podemos esquecer também da adoção pelos países do modelo neoliberal. No Brasil, o governo concretizou a implantação de tal modelo por meio de uma série de reformas que tiveram repercussões diretas para a educação. Tais reformas se concretizaram por meio das medidas que foram implantadas com a justificativa de tirar a educação da crise.

O impacto da implantação de tais medidas tem sido objeto de vários estudos, tais como os de Oliveira (2004), Hypólito (2010), entre outros. Há evidências de que a precarização e a flexibilização fazem parte do trabalho docente na atualidade. Gatti, Barreto e André (2011) alertam:

$$
\begin{aligned}
& \text { o cenário no qual os professores atuam e o foco de suas formas } \\
& \text { de atuação tem demandado complexidade crescente. A essa } \\
& \text { "complexificação" da condição docente aliam-se a precarização } \\
& \text { de suas condições de trabalho no contexto comparativo do } \\
& \text { exercício de outras profissões e as dificuldades de manter } \\
& \text { condições favoráveis para autoestima e, em sua representação, } \\
& \text { criar estima social. (GATTI; BARRETO; ANDRÉ, 2011. p. 26) }
\end{aligned}
$$

Hypólito, Vieira e Pizzi (2009) afirmam que as reformas educativas bem como a implantação de novas políticas para a organização do sistema educativo trouxeram modificações para o trabalho docente, sobre o fazer e o pensar dos professores. 
A tradução dessas mudanças sociais em reformas educacionais visando a alterar o sistema educacional em seus diferentes níveis, adequando-o às transformações da sociedade, foi imperiosa em vários países. Essas políticas públicas educacionais, atreladas ao ideário político-econômico neoliberal ou influenciadas por ele, têm no Banco Mundial a principal instituição que define políticas educacionais não só para o Brasil, mas também para os países em desenvolvimento.

Especificamente a reforma educacional paulista, iniciada em 1995 seguiu, como em todo o Brasil, orientações do Banco Mundial. Foram implantadas várias medidas como, por exemplo, a criação da função de professor coordenador pedagógico para todas as escolas, do horário de trabalho pedagógico coletivo e a escola ciclada. Foi instituído ainda o Sistema de Avaliação do Rendimento Escolar - Saresp, visando a avaliar, através de provas padronizadas e aplicadas a todo sistema escolar, o rendimento dos alunos. Outras medidas como, por exemplo, a implantação das salas-ambiente para cada componente curricular, a implantação de computadores nas escolas, a ampliação do acervo de material didático e a elaboração do projeto pedagógico de cada escola causaram também grande repercussão em toda a comunidade escolar.

Mas a medida que causou maior impacto na rede estadual de ensino foi a implantação do regime de Progressão Continuada no Ensino Fundamental (SÃO PAULO, 1997). Essa medida alterou drasticamente a organização das escolas e o cotidiano de alunos e professores.

Silva (2000), investigando a Progressão Continuada, aponta que os professores sentiam-se inseguros e que o papel docente mostrava-se confuso. Há fortes indícios de que os alunos vão para a escola, permanecem nela, mas não aprendem. Sobre isso, Bueno (2001) alerta que

[...] as crianças permanecem na escola, obtém registro de progresso escolar, mas praticamente nada aprendem. [...] Com a substituição do ensino seriado por sistema de ciclos, se, em tese, deve ser apoiado, tem sido colocado em prática sem que se ofereçam mínimas condições às unidades escolares e aos profissionais que ali atuam para que essa "não repetência" não continue a reproduzir a formação de "pseudoescolarizados", que só tem servido para engrossar as estatísticas oficiais de "melhoria da qualidade de ensino". (BUENO, 2001, p. 104)

Assim, a crise docente parece ter na implantação da reforma educacional paulista uma de suas raízes, principalmente após a Progressão Continuada. Giroux (1997) alerta que as reformas educacionais representam uma ameaça aos professores porque mostram pouca confiança na capacidade deles.

A reforma educacional ocorrida após a implantação da Lei n. 5692 em 1971 também trouxe uma série de mudanças na época. Essa medida adotada abriu as portas da escola para a maioria da população, extinguiu o exame de admissão, o primário e o ginásio. Foi criado o ensino de $1^{\circ}$ Grau obrigatório com oito anos 
de duração. A abertura atendeu uma demanda da sociedade, mas os professores fizeram muitas críticas e se mostraram contra a reforma.

Para Lüdke (1972), a resistência dos professores se assentava na ideia de que os alunos não tinham condições (pré-requisitos) para estarem na $5^{\text {a }}$ série. É possível supor que essa democratização do ensino trouxe para os professores um sério problema: como trabalhar com alunos que eles consideravam sem condições acadêmicas? A reforma da década de 1970 parece ter se esquecido de preparar os professores para receber esses alunos com um novo perfil.

Contrapondo-se à interpretação de que os professores da época eram resistentes à mudança, a tese de Sampaio (1998) permite-nos ter outra visão. Segundo ela, "os professores denunciavam o modelo de expansão quantitativa e sua intenção de nivelar por baixo o trabalho das escolas". (SAMPAIO, 1998, p. 222).

No início da década de 1980, Mizukami (1983) ilustrou a rotina pedagógica dos professores especialistas nos anos 80. Para ela, o ensino tradicional predominava na prática educacional, pois os professores detinham os conhecimentos e os transmitiam aos alunos.

A tese de Dias-da-Silva (1992) apontou que o programa a ser cumprido era a ditadura mais forte que os professores se impunham. Surgiam conflitos para os professores porque precisavam "andar com a matéria", ensinar Ciências ou Matemática.

A partir da análise desses trabalhos pode-se supor que, para os professores especialistas formados em diferentes cursos de Licenciatura, é essencial ensinar os conteúdos. Assim, o conceito de cultura docente, proposto por Pérez Gómez (2001), parece adequado para interpretar os professores especialistas e seu trabalho. Ele define a cultura dos docentes como "conjunto de crenças, valores, hábitos e normas dominantes que determinam o que este grupo social considera valioso em seu contexto profissional, assim como os modos politicamente corretos de pensar, sentir, atuar e se relacionar entre si” (PÉREZ-GÓMEZ, 2001, p. 164).

Essa definição de cultura docente engloba aspectos que vão desde formas de pensar até modos de agir. Podemos então questionar: como se configura essa cultura docente dos professores que atuam nos anos finais do Ensino Fundamental e Ensino Médio? O ensino dos conteúdos é um elemento central na cultura dos professores especialistas? A história de nossa educação mostra que esses professores sempre foram formados em cursos superiores para ensinar disciplinas específicas. Seu papel tradicional sempre foi a transmissão dos conteúdos (PEREIRA, 1969).

Nesse sentido, parece que a cultura docente dos professores especialistas configura-se a partir da centralidade no ensino dos conteúdos específicos e no domínio das habilidades acadêmicas por seus alunos. Não se trata de um saber idiossincrático ou particularizado de uma ou outra professora. Os trabalhos 
analisados apontam indícios de que se trata de concepção partilhada pelo grupo de professores especialistas.

Podemos então pensar: as várias mudanças sociais e a implantação da reforma educativa alteraram a organização das escolas públicas e o trabalho dos professores. E a cultura docente, se alterou? Os professores será que ainda mantêm um nível rígido de exigências? A matéria e o programa a ser cumprido continuam sendo os ditadores mais fortes que os professores se impõem? Dias-da-Silva (2001) afirma: "a verdade é que os professores especialistas estão perdidos perante a seu papel e função" (DIAS-DA-SILVA, 2001, p. 11).

\section{Metodologia}

Levando em consideração o contexto já colocado, este artigo, que é parte de uma Tese de Doutorado, buscou analisar especificamente os indícios de alteração na cultura docente dos professores especialistas, principalmente após a implantação da reforma educacional paulista.

Para isso, foram realizadas entrevistas em profundidade. Ouvindo o que os professores têm a falar sobre o seu próprio trabalho, é possível conhecer, analisar e interpretar aquilo que pensam e sentem (BIASOLI-ALVES; DIAS-DA-SILVA, 1992; ZAGO, 2003).

Três critérios impuseram-se para a escolha dos professores: que cada um tivesse mais de 20 anos de experiência, pois o professor, nessa fase, colocase em questionamento; que tivessem uma prática pedagógica apontada como comprometida e realizassem um trabalho referenciado pela comunidade escolar.

No total foram entrevistados dez professores, sendo dois professores de cada componente curricular: Português, Matemática, História, Geografia e Ciências. O grupo de entrevistados incluiu cinco homens e cinco mulheres. As idades deles variaram de 42 a 48 anos, e o tempo de experiência no magistério de 20 a 25 anos. As entrevistas, que foram integralmente gravadas e transcritas, duraram de 2 a 3 horas. A análise dos dados baseou-se na abordagem qualitativa de pesquisa. Biasoli-Alves e Dias-da-Silva (1992) contribuíram para o detalhamento metodológico do processo de análise de entrevistas.

\section{Resultados}

As análises trazem resultados muito interessantes. Há indícios de que a cultura docente dos professores especialistas se alterou. Considerando a formação recebida por esses professores, e comparando o papel que desempenhavam no passado, parece que estamos diante de uma nova especificidade do trabalho docente, ou diante de nova cultura docente. Alguns depoimentos ilustram isto: 
hoje você não ensina só Matemática. Em primeiro lugar, você tem que resgatar muita coisa: valores, comportamento. Está difícil trabalhar. Então nosso papel na escola hoje exige isso e a gente tem que fazer esse papel mais amplo, apesar de não ter formação para isso, apesar de muitas vezes não ter capacidade para fazer determinadas coisas.

meu papel é muito amplo. A gente tem que dar essa visão para o aluno das novas tecnologias, novas descobertas, as doenças, etc. Mas também eles vêm aqui para ter um afeto em primeiro lugar. Não se pode mais se esquecer disso. O conteúdo fica de lado porque a questão comportamental é prioridade. $\mathrm{O}$ afetivo, o lado emocional, tudo isso tem que procurar trabalhar de alguma forma. A gente tem um desgaste muito grande passando pros alunos noções de costume, de valores, de hábitos básicos que era pra eles trazerem de casa. Há vinte anos eu ensinava Ciências. Hoje eu tenho que dividir isso com outras funções.

Podemos supor que tanto as mudanças no contexto social mais amplo como as reformas implementadas colaboraram para que essa alteração acontecesse. Pérez Gómez (2001) confirma essa ideia. Segundo ele,

a cultura docente se encontra, na atualidade, numa delicada encruzilhada, vivendo uma tensão inevitável e preocupante entre as exigências de um contexto social móvel, mutável, flexível e incerto, caracterizado pela complexidade tecnológica, pela pluralidade cultural e pela dependência dos movimentos do livre mercado mundial, por um lado, e as rotinas, as convenções e os costumes estáticos e monolíticos de um sistema escolar sem flexibilidade, opaco e burocrático por outro. Nesta inevitável tensão, os docentes se encontram cada dia mais inseguros e indefesos, se sentem ameaçados por uma evolução acelerada a que não podem ou não sabem responder. (PÉREZ-GÓMEZ, 2001, p. 164)

Diversamente aos anos oitenta, pode estar havendo uma redefinição do papel dos professores, procurando conciliar, ao ensino dos conteúdos específicos, um papel afetivo e de socialização. Nessa ampliação do papel docente há a explicitação de uma diferença decisiva na cultura docente dos professores especialistas. Em alguns momentos parece que a função socializadora é até mais importante ou prioritária, e os professores parecem não ter outra alternativa a não ser desempenhar tal função. Talvez quando se adaptam a esta nova situação, ou seja, desempenham outras funções para as quais não foram formados, parecem construir então um novo papel que responde a uma nova ideia de professor que as circunstâncias exigem.

Chama a atenção essa mudança no papel dos professores e no papel da escola. Tal mudança parece atender aos interesses de um projeto que quer outro modelo de escola. Nesse sentido, os resultados confirmam Paiva (2003) que afirma estarem em questão as clássicas funções do sistema educativo. Estaremos então diante de uma nova especificidade do papel da escola e do trabalho 
docente? Estaria ocorrendo um esvaziamento ou um desvirtuamento do papel dos professores e, consequentemente, do papel da escola? A análise dos dados parece sim apontar para a construção de uma nova cultura docente.

Oliveira (2010, p. 24) reforça essa hipótese de mudança no papel e, consequentemente, na cultura docente:

muitas vezes os trabalhadores docentes são obrigados a desempenharem funções de agente público, assistente social, enfermeiro, psicólogo, entre outras. Tais exigências contribuem para um sentimento de desprofissionalização, de perda de identidade, da constatação de que ensinar às vezes não é o mais importante. (OLIVEIRA, 2010, p. 24)

Contreras (2002) reforça a ideia de que os professores estão sobrecarregados por terem que desempenhar funções cada vez mais complexas, difusas e ambíguas. Por outro lado, a importância dos conteúdos escolares continua decisiva. Quando os professores falam sobre o seu papel, explicitam a visão da disciplina que trabalham, ressaltando uma perspectiva mais pragmática e contextualizada:

hoje eu vejo a Geografia como uma coisa mais ampla. Eu não dou Amazônia sem Chico Mendes. Hoje eu paro, falo do Gandhi, da revolução que ele fez. Falo sobre o apartheid pra mostrar o que aconteceu para que isso não aconteça de novo. Que eles sintam repúdio e que valorizem um cara como Nelson Mandela.

eu procuro falar pra eles: não veja Ciências como a coisa que tá no livro e acabou. Eu procuro sempre juntar no dia-a-dia deles. Por exemplo: falo dos vermes. Pra quê? Só pra falar aqueles nomes esquisitos que têm? Você fala isso também, mas você fala que se não tiver bons modos de higiene, se não lavar as mãos antes das refeições.

Interessante observar que os professores utilizam exemplos de sua disciplina e dos conteúdos das matérias ministradas por eles para permitir que os alunos interpretem e compreendam o mundo onde vivem. Isso parece fazer parte do papel que se atribuem. A professora de Matemática argumenta a favor dessa ideia:

é o aprender a pensar. Logaritmo é chato? Eu não vou usar nunca? Talvez você não vá usar nunca. Só que tem uma coisa: ao resolver essa questão o que você teve que fazer? Elaborar uma linha de pensamento. E eu falo isso para os meus alunos: vocês têm que aprender a pensar. E a Matemática faz isso!! Eu tenho que pensar com lógica!!

Todos os professores fazem um alerta: há um discurso chegando às escolas que defende a ideia da minimização do conhecimento escolar: 
o que a diretoria de ensino tenta passar pra gente é o seguinte: "o que importa é a formação do indivíduo como um todo. Se ele não aprendeu o conteúdo de matemática, não tem importância”. Eu não vejo assim. Eu vejo o seguinte: eu sou professora de Matemática. E muita coisa ele vai precisar!

nos últimos anos começou-se a achar que a função da escola é possível sem conteúdo. É um desvirtuamento muito grande que já comprometeu. A gente não pode prescindir do conteúdo! A escola erra quando não sente necessidade do conteúdo.

desde quando comecei a lecionar, eu sinto uma degradação no papel do professor. Está ocorrendo um esvaziamento da questão do conteúdo. Está vigente hoje que a escola tem que preparar para a vida, seja lá o que signifique isso.

Esses depoimentos sinalizam a relação entre a explicitação do papel docente e o papel da escola. Ou seja, o papel que os docentes se atribuem é decorrência direta da finalidade da escola. Se no passado seu papel como professores especialistas se centrava no ensino dos conteúdos específicos, atualmente seu papel se ampliou devido à alteração no papel da escola, voltada à cidadania e Socialização. "Formar o indivíduo" e "preparar para a vida": estas expressões são frequentemente utilizadas pelos professores - repetindo muitas vezes o discurso preconizado pela reforma educacional.

Decorrente da ampliação do papel docente, estamos diante de uma mudança na especificidade do trabalho docente destes professores, porque em alguns momentos os professores "abrem mão" do acadêmico para suprir aquilo que as famílias e a sociedade não ofereceram a seus jovens alunos.

É evidente que a sociedade passou por transformações radicais que afetaram a escola. Porém, o ensino dos conteúdos, papel histórico da escola e dos professores especialistas, para onde vai? Se os alunos das camadas populares não aprenderem isso na escola, aprenderão onde? Quem vai ensiná-los?

Chama a atenção nos depoimentos a forma como os professores se expressam quando falam do próprio papel. Parece que hoje esse papel difere daquele do passado. E eles expressam com clareza que, se "antes" a prioridade era ensinar os conteúdos específicos, "hoje" isso não é mais verdadeiro. Os professores têm condições de fazer tal comparação porque todos têm 20 anos de experiência.

Talvez, as reformas educacionais podem estar negando a essência do trabalho docente quando deixam de lado os conteúdos escolares, o conhecimento das disciplinas, a interpretação da realidade através do conhecimento. Negar a importância dos conteúdos parece o mesmo que negar a importância do professor e isso incomoda a todos.

Os professores denunciam ainda algo sério: o aluno ter seis ou dez anos de escolaridade não faz diferença, pois eles apresentam as mesmas dificuldades em ler, escrever ou interpretar um texto. Poderíamos até pensar que aprenderão em 
outros lugares e através de outros meios, mas sendo adolescentes pertencentes às camadas populares, que outro lugar senão a escola para aprender? Outro elemento central que apresenta alteração é a avaliação:

hoje eu tenho muito problema para trabalhar porque de uns 15 anos pra cá, criou-se uma história de que o aluno não pode ser corrigido. Ele tem que ser corrigido sim.

a gente foi se modelando. Eu mudei muito. Não posso ser exigente como eu era antes da Progressão Continuada.

em relação à Progressão Continuada eu acho a ideia boa, embora eu seja um crítico do governo. Acho que os alunos têm capacidade de assimilação diferente, então, não tem porque você nivelar e barrar todo mundo. Eu acho que tem que haver realmente progressão. Mas o problema é que hoje essa coisa tá virando isso mesmo: não tem reprovação.

você tem que dar condições pro aluno alcançar os objetivos propostos. E é claro que se você tem um sistema de avaliação naquele rigor tradicional não é bom. Mas esse caminho também não foi bom.

o que eu acho da Progressão Continuada? Para nós ficou pior. $\mathrm{O}$ aluno chegou e falou: não adianta o senhor não dar nota para mim, porque o governo me passa. $\mathrm{Na}$ prática, então, não repete mais ninguém. $\mathrm{E}$ isso deixa a gente frustrado. Ele não conseguiu nota comigo eu vou dar nota para ele passar? Não, não vou. Você quer passar, a escola quer passar, a diretoria quer passar, o governo quer passar? Tudo bem, passe!

Nesses depoimentos chama a atenção o que eles dizem sobre a Progressão Continuada: independentemente dos alunos terem aprendido ou não, eles são promovidos. Depois da implantação da medida nas escolas estaduais paulistas, sabendo ou não, os alunos sempre são promovidos.

Embora admitam a necessidade de rebaixar o nível de exigência relacionado à avaliação, todos os professores se queixam de que os alunos apresentam o problema da falta de pré-requisitos imprescindíveis, como por exemplo, dificuldade para ler e interpretar textos.

há situações bastante preocupantes, como, por exemplo, uma criança no $6^{\circ}$ ano que não esteja habilitada para ler um texto. Isso ocorre e não pode ser encarado como normal.

o que acontece é o seguinte: quando chega ao Ensino Médio ele não sabe escrever.

o nível realmente está muito baixo. E também porque falta o pré-requisito. Então, você vai falar de um assunto, tem que voltar muito lá atrás. Você tem que responder perguntas que não era para aquele nível, entendeu? Outro dia eu estava falando da passagem do Brasil da monarquia para a república no Ensino Médio. Aí perguntaram: o que é monarquia e o que é república? 
Aí eu pensei: pelo amor de Deus!! Estou falando alguma coisa achando que é óbvio e não é.

eles chegam despreparados. Eles leem e aí? Não fazem interpretação. Eu dei uma pergunta na prova. O aluno gritava comigo porque ele não entendia a pergunta!!

Parece claro que a dificuldade dos alunos em leitura e interpretação de texto, assim como a falta de conteúdos básicos na área são aspectos que trazem problemas nucleares para o trabalho docente, tanto nos anos finais do Ensino Fundamental quanto no Ensino Médio. Um dado chama muito a atenção: a queixa de um professor de um $6^{\circ}$ ano é igual à do professor do $2^{\circ}$ ano do Ensino Médio, confirmando Bueno (2001).

Outro aspecto a ser ressaltado que também se alterou é o reconhecimento deles, que estão menos exigentes e mais lights. As justificativas apresentadas por eles parecem indicar que essa mudança foi necessária, visto que tanto o sistema de ensino quanto o próprio nível dos alunos exigiram. Assim, parece claro que não viram outra alternativa a não ser rebaixar seu nível de exigência para com as classes.

Como provoca Sampaio (2003):

forma-se uma nova imagem de alunos, de professor e de escola, na qual indiscutivelmente se desenvolvem padrões pedagógicos diferentes da escola tradicional. A função social dessa escola ainda está por ser investigada [...] De que noções, conceitos e habilidades os alunos estão se apropriando? O que está sendo oferecido a eles? (SAMPAIO, 2003, p. 17-18)

Através da voz desses professores, evidencia-se outro modelo de escola que vem sendo implantado, modelo este muito distante daquele originalmente pensado para ela, que nasceu com uma função social e cultural bastante clara: levar até as novas gerações um legado de ideias através da socialização do conhecimento historicamente valorizado e produzido.

Ressaltamos, ainda, que analisando o atual contexto e comparando com pesquisas produzidas no passado, percebemos uma ampliação do papel docente, traduzida no desempenho de várias tarefas e no abandono do aspecto acadêmico como central. Além disso, temos novos elementos que parecem indicar alteração na cultura docente de professores especialistas (PÉREZ GÓMEZ, 2001).

Por outro lado, a finalidade histórica de seu trabalho-ensinar-parece ameaçada, e isso incomoda os professores. Destacamos que eles não se recusam a desempenhar um papel socializador, entretanto é forte a reação deles à formação dos "pseudoescolarizados" (BUENO, 2001). Claramente eles não pactuam com o fato dos alunos saírem da escola sem saber, com um concluinte do Ensino Fundamental incapaz de interpretar uma instrução de um problema de Matemática e escrever uma redação. 
O problema é grave porque saber ler e interpretar um texto é uma necessidade anterior ao domínio de qualquer conteúdo específico. Mas, além da dificuldade na leitura e escrita, a fragilidade no domínio de conteúdos específicos também compromete o ensino e a aprendizagem de outras disciplinas, como denunciam alguns professores:

o cara está no $2^{\circ}$ ano do Ensino Médio e não sabe nada sobre o descobrimento do Brasil? Eu estou trabalhando na Literatura a carta do Pero Vaz de Caminha e ele não sabe nada disso? Não tem condições de interpretar essa carta porque ele não teve aula de História. Então é complicado. Como eu vou fazer? Aí eu dou uma aulinha de História referente ao assunto que está sendo estudado.

eu estou trabalhando, por exemplo, a hidrografia da África, a importância do Nilo. Aí eu pergunto: "a professora de História falou com vocês sobre esse assunto? Vocês estudaram as civilizações egípcias? Viram a importância do Nilo para essas civilizações?” “Não, não vimos!!” Então eu dou para que encaixe e vá embora.

Percebemos que os professores até procuram resolver esse problema, ainda que com ensino aligeirado. Então questionamos: por que os alunos estão "passando" pela escola e não estão aprendendo o que é esperado? Será que não há relação entre o fato dos alunos não saberem interpretar textos e o fato dos professores terem um papel mais ampliado? Será que nesse papel ampliado, o ensino e a aprendizagem dos conteúdos específicos estão sendo minimizados? Tais questões precisam ser melhor investigadas, mas é possível supor que os professores enfrentam confronto e não adequação de expectativas, ou estão, como coloca Pérez Gómez, em uma encruzilhada.

Nesse cenário, identificamos um aspecto decisivo para o entendimento da mudança na cultura docente e para a compreensão desse grave processo de enfraquecimento da escola. As análises mostram que os professores foram pressionados a rebaixar as exigências, principalmente depois da implantação da Progressão Continuada. Estão menos exigentes e isso parece mais um indício de que a cultura docente se alterou.

É possível perceber que o rebaixamento das exigências vem ligado à forma de avaliar: não podem ser tão exigentes como antes porque todos os alunos serão promovidos. Porém, supondo que esse rebaixamento não se reduza à avaliação, mas ao trabalho docente como um todo, pode-se pensar que os professores também estão ensinando menos, porque seu papel se ampliou e há menos tempo para ensinar.

Talvez essa fragilidade no domínio dos conteúdos escolares e o rebaixamento das exigências sejam, então, consequências de um processo externo à sala de aula, que vai desde a necessidade de obtenção de índices de promoção escolar para captação de recursos no Banco Mundial até o acúmulo de aulas e escolas no cotidiano dos professores. Entretanto, é na sala de aula, com os alunos 
"pseudoescolarizados", que se materializa a fragilidade das reformas educacionais e do trabalho docente.

Nesta situação questionamos: que outra atitude eles poderiam ter, se são pressionados a promover alunos sem condições? O que fazer se estão desempenhando outras funções porque a família e a sociedade estão se omitindo no cumprimento de seus papéis?

Investigar tais questões é necessário. Assim, acreditamos que esse trabalho traz contribuições significativas para a formação bem como a atuação dos professores especialistas. Ao procurar analisar, na concepção dos professores especialistas, a questão do ensino dos conteúdos - aspecto central - foi possível observar que, subjacente aos baixos indicadores de rendimento escolar das escolas públicas, pode estar a mudança no papel e, consequentemente, na cultura, docente dos professores especialistas. $\mathrm{E}$ isso, certamente, precisa ser discutido e problematizado nos cursos de Licenciatura.

Nesse cenário, percebemos um sentimento geral de insatisfação. Entretanto, essa insatisfação não se traduz em uma vontade de abandonar a profissão, uma forma de enfrentar tantos problemas e dificuldades. Há um desejo de continuar, porque, apesar de tudo, gostam do trabalho que realizam e acreditam nele. Para isso não são poucos os desafios. Como ressalta Oliveira (2003):

[...] estamos diante de novos padrões de organização do trabalho escolar, exigentes de novo perfil de trabalhadores docentes [...] Os trabalhadores docentes se veem forçados a dominar práticas e saberes antes desnecessários ao exercício de suas funções [...] São muitas as novas exigências que esses profissionais se veem compelidos a responder. Sendo apresentadas sob o manto da novidade, essas exigências são tomadas como um imperativo por esses trabalhadores. Como se não pudesse haver voz dissonante, acabam por submeter-se a um discurso sobre a prática que se confunde com a própria prática, num mimetismo, numa falsa pragmática. (OLIVEIRA, 2003, p. 33-34)

Parece claro que esses novos padrões de organização do trabalho escolar e as novas exigências feitas aos profissionais do ensino são seus grandes desafios hoje. As análises sobre o trabalho docente são cada vez mais difíceis de serem realizadas e o âmbito de compreensão dele se amplia. Há inúmeras questões a serem respondidas e analisadas em profundidade. Assim, novas pesquisas e estudos se fazem necessários para que possamos compreender melhor o trabalho docente, apreender suas contradições e entender a trama de relações que o envolve. A pesquisa é, sem dúvida, um meio de chegarmos a algumas respostas que poderão servir de base para a construção de uma escola de qualidade para todo cidadão brasileiro. 


\section{Referências}

APPLE, M. W. Trabalho docente e textos: economia política das relações de classe e de gênero na educação. Porto Alegre: Artes Médicas, 1995.

BIASOLI ALVES, Z. M. M. e DIAS-DA-SILVA, M. H. G. F. Análise qualitativa de dados de entrevista: uma proposta. Paidéia, n. 2, p. 61-69, 1992.

BRASIL. Lei 5692, de 12 de agosto de 1971. Fixa diretrizes e Bases para o Ensino de $1^{\circ}$. E $2^{\circ}$. Graus, e dá outras providências. Disponível em: <http://www.jusbrasil.com.br/ legislacao/128525/lei-de-diretrizes-e-base-de-1971-lei-5692-71>. Acesso em: 8 dez. 2012.

BUENO, J. G. S. Função social da escola e organização do trabalho pedagógico. Revista Educar, n. 17, p. 101-110, 2001.

CONTRERAS, J. D. A autonomia de professores. São Paulo: Cortez, 2002.

CUNHA, M. I. Profissionalização docente: contradições e perspectivas. In: VEIGA, I. P. A.; CUNHA, M. I. (Org.). Desmistificando a profissão do magistério. Campinas: Papirus, 1999. p.127-147.

DIAS-DA-SILVA, M. H. G. F. O professor como sujeito do fazer docente: a prática pedagógica nas 5as séries. 1992. 262 f. Tese (Doutorado em Educação). Faculdade de Educação, Universidade de São Paulo, São Paulo, 1992.

. Projeto pedagógico e escola de periferia: sonho ou pesadelo. In: Reunião da ANPed., 24, 2001. Caxambu: ANPed, 2001. 1 CD-ROM.

ESTEVE, J. M. Mudanças sociais e função docente. In: NÓVOA, A. (Org.). Profissão Professor. Porto: Porto, 1995, p. 93-124.

GATTI, B. A.; BARRETO, E. S. S. e ANDRÉ, M. E. D. A. Políticas docentes no Brasil: um estado da arte. Brasília: UNESCO, 2011, 300 p.

GIROUX, H. Os professores como intelectuais. Porto Alegre: Artes Médicas, 1997.

HYPÓLITO, A. M. Trabalho docente e profissionalização: sonho prometido ou sonho negado? In: VEIGA, I. P. A.; GUNHA, M. I. (Org.) Desmistificando a profissionalização do magistério. Campinas: Papirus, 1999. p. 81-100.

HYPÓlito, A. M. Políticas Curriculares, estado e regulação. Educação e Sociedade, Campinas, v. 31, n. 113, out./dez, p. 1337-1354, 2010.

.; VIEIRA, J. S.; PIZZI, L. C. V. Reestruturação curricular e auto-intensificação do trabalho docente. Currículo sem Fronteiras, v. 9, n. 2, jul./dez, p. 100-112, 2009. Disponível em: <http://www.curriculosemfronteiras.org $>$.

LÜDKE, H. et al. A reforma do ensino médio vista pelos professores do ensino secundário de São Paulo. Pesquisa e Planejamento, v. 14, p. 3-137, 1972.

MIZUKAMI, M. G. N. Ensino: o que fundamenta a ação docente? 1983. Tese (Doutorado em Educação) - Pontifícia Universidade Católica do Rio de Janeiro, 1983.

OLIVEIRA, D. A. A reestruturação do trabalho docente: precarização e flexibilização. Educação e Sociedade, Campinas, v. 25, n. 89, set./dez. p. 1105-1126, 2004.

As reformas educacionais e suas repercussões sobre o trabalho docente. In: OLIVEIRA, D. A. (Org.). Reformas educacionais na América Latina e os trabalhadores docentes. Belo Horizonte: Autêntica, 2003. p. 13-35

. Os trabalhadores da educação e a construção política da profissão docente no Brasil. Educar em Revista, Curitiba, n. especial, p. 17-35, 2010. Disponível em <http://www.scielo. $\mathrm{br} /$ scielo.php? script $=$ sci_arttext\&pid $=\mathrm{S} 0104-40602010000400002 \& \operatorname{lng}=$ pt $\& \mathrm{nrm}=$ iso $>$. Acesso em: 09 maio 2012. 
PAIVA, V. História da educação popular no Brasil. 6. ed. São Paulo: Loyola, 2003.

PEREIRA, J. B. B. A escola secundária numa sociedade em mudança. São Paulo: Pioneira, 1969.

PERÉZ-GÓMEZ, A. A cultura escolar na sociedade neoliberal. Porto Alegre: Art Méd. 2001.

SAMPAIO, M. M. Um gosto amargo de escola. São Paulo: EDUC/Fapesp, 1998.

. A escola no centro da pesquisa: caminhos e problemas. In: Reunião da ANPed, 26, Poços de Caldas: ANPed, 2003. 1 CD-ROM.

SÃO PAULO (1997). Conselho Estadual de Educação. Deliberação 9 - Institui a progressão continuada na rede paulista de ensino. São Paulo: CEE, 1997.

SILVA, R. C. Progressão continuada ou reprovação: camuflagem ou compromisso? Investigando saberes de professoras primárias e secundárias da escola pública. 2000. $183 \mathrm{f}$. Dissertação (Mestrado em Educação Escolar) - UNESP, Faculdade de Ciências e Letras. Araraquara. 2000

ZAGO, N. A entrevista e seu processo de construção: reflexões com base na experiência prática de pesquisa. In: ZAGO, N.; CARVALHO, M. P.; VILELA, R. A. T. (Org.). Itinerários de pesquisa: perspectivas qualitativas em Sociologia da Educação. Rio de Janeiro: D P \& A, 2003. p. 287-309.

* Gisela do Carmo Lourencetti - Professora Doutora do Mestrado em Educação do Centro Universitário Moura Lacerda, Ribeirão Preto, São Paulo, Brasil.

\section{Correspondência}

Gisela do Carmo Lourencetti - Centro Universitário Moura Lacerda, Mestrado em Educação.

Rua Padre Euclides, 995 - Campos Elíseos

CEP: 14085-420 - Ribeirao Preto, São Paulo - Brasil

E-mail: glourencetti@ig.com.br

Recebido em 27 de julho de 2012

Aprovado em 07 de março de 2013 